\title{
Positioning Trocars for Performing Sleeve Gastrectomy. Points of Controversy
}

\author{
Radwan Kassir • Patrice Lointier • Christophe Breton • \\ Jean Gugenheim • Olivier Tiffet • Imed Ben Amor • \\ Pierre Blanc
}

Published online: 17 September 2014

(C) Springer Science+Business Media New York 2014

\section{Introduction}

Sleeve gastrectomy is not as straightforward as one might think and requires meticulous dissection and a number of operation principles [1]. There are many technical controversies which explain why there is no standardised technique in 2014 and the difficulty in interpreting published results. We discuss the controversial subject of the positioning trocars.

\section{Points of Controversy}

There are as many trocar numbers and positions as there are surgeons (1 to 7 trocars) [2,3]. We feel that the arrangement we describe is ergonomic as the trocars are inserted parallel to the greater curve of the stomach [4]. It also allows the pillar to be approached both anteriorly and posteriorly. The correct fixed reference anatomical landmark in obese patients is the xiphoid process and not the umbilicus. If the anatomy permits, the procedure can therefore be performed with three trocars, whereas four or five are used if the procedure is difficult. Surgery using a single incision has been described, although

R. Kassir $(\bowtie) \cdot$ O. Tiffet

Department of Bariatric Surgery, CHU Hospital, Jean Monnet University, Avenue Albert Raimond, 42270 Saint-Étienne, France

e-mail: radwankassir42@hotmail.fr

\section{P. Lointier}

Department of Digestive Surgery, Clinique de la Châtaigneraie, Beaumont, France

\section{Breton · P. Blanc}

Department of Digestive Surgery, Clinique Chirurgicale Mutualiste de Saint-Étienne, Saint-Étienne, France

J. Gugenheim • I. Ben Amor

Department of Bariatric Surgery, Archet 2 Hospital, University Hospital of Nice, Nice, France

it has not been proved to have benefit and is not recommended for surgeons when they carry out their first procedures [5]. In the same way as positioning the ring, the paraxiphoid trocar can be replaced with a Veress needle if the left lobe of the liver is not large [6, 7]. If it is, the trocar for the liver retractor is inserted subcostally on the right [4].

Conflict of Interest The authors (Radwan Kassir, Patrice Lointier, Christophe Breton, Jean Gugenheim, Olivier Tiffet, Imed Ben Amor, Pierre Blanc) have no conflicts of interests to declare in relation to this article.

Statement of Informed Consent Informed consent was obtained from all individual participants included in the study.

Statement of Human and Animal Rights Informed consent was obtained from all individual participants included in the study.

\section{References}

1. Kassir R, Breton C, Lointier P, et al. Laparoscopic Roux-en-Y gastric bypass with hand-sewn gastrojejunostomy using an absorbable bidirectional monofilament barbed suture: review of the literature and illustrative case video. Surg Obes Relat Dis. 2014;10:560-1.

2. Gadiot RPM, Biter LU, Zengerink HJF, et al. Laparoscopic sleeve gastrectomy with an extensive posterior mobilization : technique and preliminary results. Obes Surg. 2012;22:320-9.

3. Kassir R, Tiffet O, Breton C, et al. A useful tip for open laparoscopy. Surg Obes Relat Dis. 2014.

4. Dhahri A, Verhaeghe P, Hajji H, et al. Sleeve gastrectomy: technique and results. J Visceral Surg. 2010;147S:e39-46.

5. Huang CK, Tsai JC, Lo CH, et al. Preliminary surgical results of single incision transumbilical laparoscopic bariatric surgery. Obes Surg. 2011;21:391-6.

6. Mittermair R, Pratschke J, Sucher R. Single-incision laparoscopic sleeve gastrectomy. Am Surg. 2013;79:393-7.

7. Gianni S, De Luca M, Oscar B, et al. Veress needle : a simple liver retraction technique for lap band positioning in SILS. Obes Surg. 2012;22:190-1. 